\title{
əThe Impact of Warm and Moist Airmass Perturbations on Arctic Mixed-Phase Stratocumulus
}

\author{
GESA K. EIRUND \\ Institute for Atmospheric and Climate Science, ETH Zurich, Zurich, Switzerland \\ ANNA POSSNER \\ Institute for Atmospheric and Environmental Sciences, Goethe-University Frankfurt, Frankfurt, Germany \\ ULRIKE LOHMANN \\ Institute for Atmospheric and Climate Science, ETH Zurich, Zurich, Switzerland
}

(Manuscript received 9 March 2020, in final form 11 August 2020)

\begin{abstract}
The Arctic is known to be particularly sensitive to climate change. This Arctic amplification has partially been attributed to poleward atmospheric heat transport in the form of airmass intrusions. Locally, such airmass intrusions can introduce moisture and temperature perturbations. The effect of airmass perturbations on boundary layer and cloud changes and their impact on the surface radiative balance has received increased attention, especially over sea ice with regard to sea ice melt. Utilizing cloud-resolving model simulations, this study addresses the impact of airmass perturbations occurring at different altitudes on stratocumulus clouds for open-ocean conditions. It is shown that warm and moist airmass perturbations substantially affect the boundary layer and cloud properties, even for the relatively moist environmental conditions over the open ocean. The cloud response is driven by temperature inversion adjustments and strongly depends on the perturbation height. Boundary layer perturbations weaken and raise the inversion, which destabilizes the lower troposphere and involves a transition from stratocumulus to cumulus clouds. In contrast, perturbations occurring in the lower free troposphere lead to a lowering but strengthening of the temperature inversion, with no impact on cloud fraction. In simulations where free-tropospheric specific humidity is further increased, multilayer mixed-phase clouds form. Regarding energy balance changes, substantial surface longwave cooling arises out of the stratocumulus break-up simulated for boundary layer perturbations. Meanwhile, the net surface longwave warming increases resulting from thicker clouds for airmass perturbations occurring in the lower free troposphere.
\end{abstract}

KEYWORDS: Arctic; Inversions; Cloud radiative effects; Clouds; Cloud resolving models

\section{Introduction}

Observations as well as model simulations show that the Arctic has warmed in recent decades at a rate 2-3 times higher than the global average (Cohen et al. 2014; Pithan and Mauritsen 2014), a phenomenon termed Arctic amplification (Serreze and Barry 2011). Arctic amplification has been found to be strongest in late fall and winter and to be bottomamplified (Screen and Simmonds 2010). The underlying causes of Arctic amplification remain highly debated. On the one hand, some studies highlight the importance of local forcing and feedbacks (e.g., Kay et al. 2012; Stuecker et al. 2018), while on the other hand, anomalous poleward atmospheric heat transport was found to be one of the main contributors to the recent Arctic temperature increase (Alexeev et al. 2005; Graversen and Wang 2009; Kapsch et al. 2013; Mortin et al. 2016; Dahlke and Maturilli 2017). Anomalous heat transport can occur in the form of pulses of warm and moist air, so-called warm and moist air intrusions (Pithan et al. 2018). Airmass intrusions appear throughout the year and take about 5 days to

๑ Denotes content that is immediately available upon publication as open access.

Corresponding author: Gesa K. Eirund, gesa.eirund@env.ethz.ch cross the Arctic (Pithan et al. 2018). In addition to a surface temperature rise, warm and moist air intrusions have contributed to extreme events such as the 2012 Greenland ice sheet melting (Bennartz et al. 2013; Solomon et al. 2017) and Arctic sea ice variability (Mortin et al. 2016; Persson et al. 2017; Yang and Magnusdottir 2017; Kapsch et al. 2019). Changes in sea ice extent can in turn amplify the ongoing warming. A reduction in surface albedo (Curry et al. 1995), an altered temperature lapse rate (Pithan and Mauritsen 2014), and increased turbulent fluxes, which contribute to an enhanced boundary layer water vapor content (Semmler et al. 2016), are all consequences of a reduced Arctic sea ice cover.

Low-level cloud cover is also tightly linked to surface and boundary layer properties in the Arctic (e.g., Schweiger et al. 2008; Liu et al. 2012; Palm et al. 2010). Arctic boundary layer and low-level cloud properties have indeed been found to be highly impacted by processes related to Arctic amplification. More exposed ocean surface could potentially increase boundary layer turbulence and aerosol emissions, which in turn may increase and thicken the clouds (e.g., Schweiger et al. 2008; Gilgen et al. 2018; Eirund et al. 2019b). The response in cloud thickness to sea ice melt, however, is strongly dependent on the season (Morrison et al. 2018).

Clouds represent a key component determining the radiative balance at the surface. As polar clouds often appear as 
low-level mixed-phase clouds (MPCs; Shupe 2011), any interactions are complicated by the presence of three thermodynamical phases within the cloud system (i.e., water vapor, ice, and liquid water) as compared to a pure liquid or ice cloud. Several cloud characteristics on the micro- and macroscale such as the phase partitioning and the cloud droplet and ice crystal number and size distributions (Curry et al. 1996; Tan and Storelvmo 2019), as well as the cloud regime (Eirund et al. 2019a), can impact the radiative properties of the cloud field. Hence, a better understanding of changing cloud properties in the context of Arctic amplification can help to constrain climate change signals and climate sensitivity in the Arctic (Tan et al. 2016).

Various observational studies focusing on the whole Arctic region (Johansson et al. 2017; Liu et al. 2018; Messori et al. 2018) as well as individual case studies (Tjernström et al. 2015; Persson et al. 2017; Knudsen et al. 2018; Tjernström et al. 2019) found an impact of warm and moist airmass intrusions on cloud and boundary layer properties. However, not only the magnitude, but also the sign of change differed across previous studies. Johansson et al. (2017) noted a destabilization of the boundary layer during water vapor intrusions in satellite observations. In addition, a lifting or weakening of the capping temperature inversion has been observed across the Arctic (Johansson et al. 2017; Messori et al. 2018). On the contrary, if warm air enters the Arctic above a layer of dense, cold air overlying a sea ice surface, the intrusion leads to a strengthening of the inversion (Tjernström et al. 2015). Over most of the Arctic, cloud height as well as cloud fraction have been found to increase during warm air intrusions (Johansson et al. 2017), with the largest impact in spring over multiyear sea ice. Similarly, Tjernström et al. $(2015,2019)$ observed increased cloud fraction and fog formation during warm air intrusions over sea ice during the Arctic Clouds in Summer Experiment (ACSE) in summer 2014. Meanwhile, Knudsen et al. (2018) observed decreasing cloud fraction and increasing cloud height over sea ice and open ocean west of Svalbard in a transition from a cold to a warm period during the Arctic Cloud Observations Using Airborne Measurements during Polar Day (ACLOUD) campaign combined with the Physical Feedbacks of Arctic Boundary Layer, Sea Ice, Cloud and Aerosol (PASCAL) ship cruise in early summer 2017.

Airmass intrusions have been observed to occur at different altitudes. The intrusion height however may be important for its effect on boundary layer and cloud characteristics. Woods and Caballero (2016) found moist air intrusions to occur primarily in the boundary layer, with a maximum temperature anomaly of up to $6 \mathrm{~K}$ near the surface and a maximum specific humidity anomaly of $0.7 \mathrm{~g} \mathrm{~kg}^{-1}$ near the inversion at the time of the intrusion passage. Tjernström et al. (2015) observed temperature and specific humidity maxima within the lower kilometers of the troposphere, overlying a cold and dry surface layer. However, analyzing several inversion cases during ACSE, Tjernström et al. (2019) found that for cases with constant or decreasing moisture with height the amount of low cloud cover was lower than for any other set of conditions. Warm and moist anomalies during airmass intrusions have also been found to persist throughout the lowest $300 \mathrm{hPa}$ of the troposphere, within and above the shallow boundary layer and surface-based inversion (Knudsen et al. 2018). These varying intrusion altitudes may explain contrasting results in observational studies regarding cloud adjustments to airmass changes.

However, observational studies are linked to the prevailing meteorological conditions and represent specific case studies. In this regard, semi-idealized model simulations in addition to observational evidence will help to constrain processes responsible for Arctic boundary layer cloud changes during airmass transitions in a controlled framework. As cloud adjustments to external forcing can occur within a few hours (Neggers et al. 2019) and on small spatial scales, cloud-resolving model simulations on time scales of a day are able to capture cloud changes in response to airmass perturbations. In this study, we investigate the impact of warm and moist airmass intrusions in the form of temperature and moisture perturbations on boundary layer mixed-phase stratocumulus clouds in cloud-resolving model simulations. Our simulations are based on observations obtained during the Aerosol-Cloud Coupling and Climate Interactions in the Arctic (ACCACIA) campaign, which took place in the European Arctic in March 2013 (Lloyd et al. 2015; Young et al. 2016). While previous studies focused on perturbations of lowlevel clouds to airmass intrusions over sea ice (Tjernström et al. 2015; Persson et al. 2017; Tjernström et al. 2019), we focus our analysis on stratocumulus clouds over the open ocean. As in the annual average, around $76 \%$ of the Arctic Ocean is cloud covered (Chernokulsky et al. 2017), and the Arctic is expected to become cloudier with ongoing sea ice loss (Liu et al. 2012, 2018; Gilgen et al. 2018), marine cloud adjustments to airmass perturbations may become more relevant in the future. In addition, the Atlantic sector has been found to represent an important pathway for airmass intrusions entering the Arctic (Yang and Magnusdottir 2017), which leads to marine low-level clouds in the ACCACIA region being subject to airmass perturbations on a regular basis. Compared to previous studies conducted over sea ice, the effect of warm and moist airmass perturbations may be dampened in the generally more turbulent and moister boundary layer over the open ocean, which remains to be explored and poses a novel aspect to our study. To investigate the cloud state and its feedback on vertical moisture and temperature structures in altered airmasses, we simulate the cloud evolution in a perturbed environment (i.e., representing a state after an airmass passage), where temperature and moisture anomalies are present as initial perturbations. To add to existing case studies over sea ice and to disentangle the impact of the intrusion height, we performed a series of experiments with initial temperature and moisture anomalies below and above the boundary layer inversion.

\section{Model setup and perturbation experiments}

\section{a. Model evaluation and setup}

Our experiments are performed using the Consortium for Small-Scale Modeling (COSMO) model in its configuration for idealized large-eddy simulations (LES) (Schättler et al. 2000). COSMO LES has been frequently used to analyze Arctic MPCs and has been able to simulate several case studies according to observations (Loewe et al. 2017; Possner et al. 2017; 
Stevens et al. 2018; Eirund et al. 2019a,b). As in Eirund et al. (2019a,b) we simulate a single-layer mixed-phase marine stratocumulus deck observed during the ACCACIA campaign on 23 March 2013 (Lloyd et al. 2015; Young et al. 2016). Our simulations are initialized with measured profiles from the dropsonde number 5 released during the campaign over the open ocean. The observed humidity has been increased by $20 \%$ to account for the dry bias in the radiosonde data (Ralph et al. 2005; Young et al. 2016). The simulated domain covers a $70 \mathrm{~km} \times 70 \mathrm{~km}$ area around the dropsonde location $\left(75^{\circ} \mathrm{N}, 24.5^{\circ} \mathrm{E}\right)$.

The horizontal resolution is $200 \mathrm{~m}$; the vertical resolution is variable and specified with 20 to $50 \mathrm{~m}$ throughout the boundary layer and coarser resolution above cloud top. The temporal resolution is $2 \mathrm{~s}$ and all simulations have been run for $24 \mathrm{~h}$, including a 2-h spinup period. The simulations are performed during nighttime conditions; that is, shortwave (SW) incoming radiation was set to zero at any time. Radiation is parameterized interactively using the Ritter and Geleyn (1992) radiation scheme. At the cloud-resolving scale turbulent eddies initiating convection can be resolved and shallow and deep convection does not require a parameterization. For turbulent diffusion, a 3D Smagorinsky-Lilly closure scheme is used (Langhans et al. 2012). The Seifert and Beheng (2006) two-moment scheme is applied to parameterize cloud microphysical tendencies. The scheme considers five hydrometeor classes (cloud droplets, rain drops, cloud ice, snow, and graupel) and their bulk mass and number concentrations. Cloud droplet activation is calculated from a fixed ambient cloud condensation nuclei (CCN) concentration according to Köhler theory (Nenes and Seinfeld 2003). The background CCN mode is represented by a lognormal size distribution $(0.2-\mu \mathrm{m}$ mean diameter and 1.5 standard deviations) and is initialized with a concentration of $100 \mathrm{~cm}^{-3}$, according to the observed cloud droplet number concentration (Young et al. 2016). Prognostic ice nucleating particles (INPs) are treated as in Solomon et al. (2015) and implemented as described in Possner et al. (2017). This scheme parameterizes the DeMott et al. (2015) INP temperature dependence over a temperature interval from 258 to $250.5 \mathrm{~K}$. INP concentrations were initialized with $3.3 \mathrm{~L}^{-1}$ according to observations from Young et al. (2016). Regarding ice multiplication processes, the Hallett-Mossop mechanism (Hallett and Mossop 1974) is the only secondary ice mechanism included in our model, which is however inefficient at temperatures below $-8^{\circ} \mathrm{C}$. Following previous COSMO configurations (Stevens et al. 2018; Eirund et al. 2019a,b), ice crystals and snowflakes are assumed to be dendrites. Surface fluxes are calculated interactively in the model based on bulk formulations (Raschendorfer 2001) and range between -16 and $-23 \mathrm{~W} \mathrm{~m}^{-2}$ (between -22 and $-31 \mathrm{~W} \mathrm{~m}^{-2}$ ) in terms of the latent (sensible) heat flux. The sea surface temperature (SST) of the underlying ocean was fixed at $0^{\circ} \mathrm{C}$ (within the range of reanalysis; Young et al. 2018) and the surface roughness was set to $0.0002 \mathrm{~m}$ (Wieringa 1980). Divergence was prescribed as a linearly increasing function from zero at the surface to $4 \times 10^{-6} \mathrm{~s}^{-1}$ at the inversion height and was kept constant above. To study the impact of warm air perturbations on cellular mesoscale cloud organization, largescale horizontal advection was ignored in our simulations.
Warming driven by subsidence heating was compensated by a corresponding negative temperature tendency.

The initial conditions used for model initialization are shown in Fig. 1. The black lines denote the observed temperature and specific humidity profiles as measured with the dropsonde in Young et al. (2016). The local conditions during ACCACIA are characterized by a temperature inversion at $1.3 \mathrm{~km}$, capping a single-layer MPC (Young et al. 2016; also see Figs. 1 and 2 herein). Our modeled MPC has cloud properties comparable to observations and covers a similar vertical range, with the main cloud layer (i.e., where $>1 \%$ of the domain grid points are cloud covered) between 0.6 and $1.4 \mathrm{~km}$ (Fig. 2). The MPC comprises a supercooled layer at cloud top in which ice crystals form and precipitate, which is a common feature of Arctic MPCs (Morrison et al. 2012). Averaged total column water vapor in our simulation is $4.5 \mathrm{~kg} \mathrm{~m}^{-2}$, which is well within the range of observed total column water vapor in the Arctic in spring ( $\sim 2-7.5 \mathrm{~kg} \mathrm{~m}^{-2}$ north of $80^{\circ} \mathrm{N}$; Serreze et al. 2012; Alraddawi et al. 2018) and thus represents a typical case for a high-latitude marine boundary layer.

\section{b. Perturbation experiments}

To investigate the impact of warm and moist airmass perturbations on marine Arctic mixed-phase boundary layer stratocumulus, we performed one unperturbed simulation initialized with the observed atmospheric conditions (Control) and a set of five perturbation simulations (Table 1 and Fig. 1). To resemble cloud formation in altered airmasses, we changed the initial temperature and specific humidity profiles within the boundary layer and above the inversion layer in the lower free troposphere. We performed one simulation each to represent only warm air initial perturbations, one simulation each of warm and moist air perturbations at constant relative humidity, and one simulation for a warmer perturbation with increased relative humidity. The amplitude of the temperature and humidity anomalies has been chosen to resemble perturbations by warm air intrusions as presented in Woods and Caballero (2016). For warm air perturbations, the temperature profile was increased by $5 \mathrm{~K}$ at the surface (W_BL) and in the lower free troposphere (W_LFT) and then gradually decreased to match the original profile at the inversion layer and in the free troposphere, respectively. In the case of only warm air perturbations, relative humidity was calculated according to the warmer temperature profile. For warm and moist air perturbations, specific humidity was increased such that the relative humidity remained constant with respect to the Control simulation (WM_BL, WM_ LFT). The warm and additional moist airmass perturbation includes an increase in specific humidity by $0.7 \mathrm{~g} \mathrm{~kg}^{-1}$ (WhM_LFT).

\section{Thermodynamic profiles}

Figure 3 shows the ice-liquid potential temperature $\left(\theta_{\mathrm{il}}\right.$; Tripoli and Cotton 1981) and total water content $\left(q_{t}=q_{c}+\right.$ $q_{v}+q_{i}$ ) averaged over 2 to $24 \mathrm{~h}$. The boundary layer in Control is stably stratified with a shallow unstable surface layer as a result of cold air overlying a relatively warm ocean. Further aloft the boundary layer features a pronounced temperature inversion and a small moisture inversion at $1.2 \mathrm{~km}$ height, capping the low-level cloud layer shown in Fig. 2. 
a) Initial boundary layer perturbation
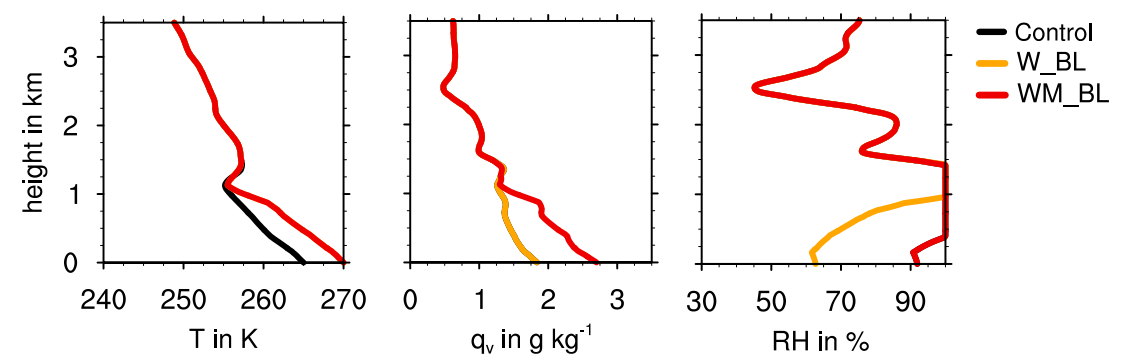

b) Initial perturbation in the lower free troposphere
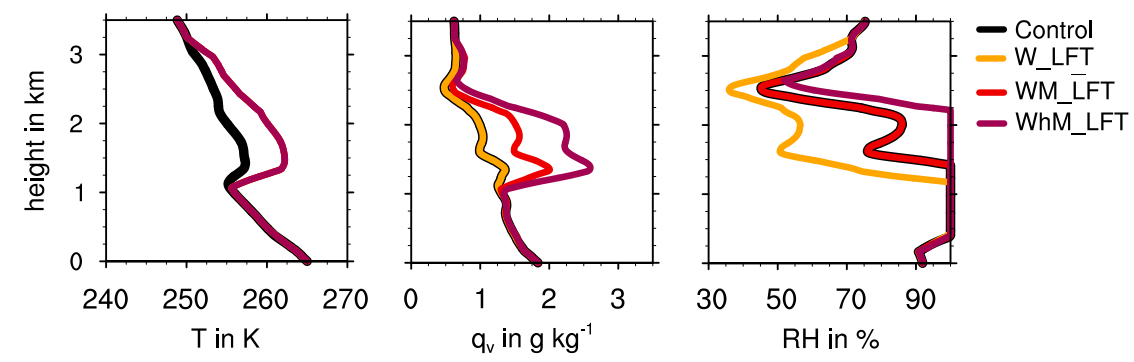

FIG. 1. (left to right) Initial temperature $(T)$, specific humidity $\left(q_{v}\right)$, and relative humidity $(\mathrm{RH})$ profiles for (a) initial boundary layer perturbations and (b) initial perturbations in the lower free troposphere. Note that the measured cloud condensate has been added to the profile to account for cloud presence.

Warm and moist air boundary layer perturbations increase $\theta_{\mathrm{il}}$ throughout the subcloud layer. The temperature inversion is lifted and weakened in W_BL and WM_BL compared to Control (Fig. 3a). The boundary layer destabilizes, but remains stably stratified in the perturbed simulations as the vertical $\theta_{\mathrm{il}}$ gradient remains positive. Moisture accumulates in the lower part of the boundary layer, which strengthens the negative vertical gradient in $q_{t}$.

In simulations featuring airmass perturbations above the boundary layer, the inversion is strengthened and pushed downward (Fig. 3b). This effect is strongest in WhM_LFT, where the temperature inversion is approximately $250 \mathrm{~m}$ lower than in Control. Additionally, the temperature variability above the inversion substantially increases to around $2 \mathrm{~K}$ in W_LFT and WM_LFT and up to $5 \mathrm{~K}$ in WhM_LFT.

In the case of warm and moist airmass perturbations, total moisture increases throughout the lower $3.5 \mathrm{~km}$. Particularly in WhM_LFT, total moisture is substantially increased below and above the inversion layer. For only warm air perturbations, $q_{t}$ remains similar as in Control in the lower free troposphere and at the surface. However, within the boundary layer, the warming and intensified inversion promote increased $q_{t}$ in W_LFT as compared to Control, which is further discussed in section 5 .

\section{Stratocumulus response to boundary layer perturbations}

To represent airmass intrusions with anomalies close to the surface as reported by Woods and Caballero (2016), we first analyze cloud changes from our boundary layer perturbation simulations with respect to the stratocumulus cloud in the Control simulation. In both boundary layer perturbation simulations, the boundary layer deepens and the cloud top rises throughout the simulated time period (Figs. $3 \mathrm{a}$ and $5 \mathrm{~g}$ ). The deepened boundary layer and the lifted cloud top have implications for the spatial cloud structure. Figure 4 shows the temporal evolution of the liquid water path (LWP) and regions of the ice water path (IWP) exceeding the 85th percentile of the spatial IWP distribution for the Control simulation and both boundary layer perturbation simulations. The Control case is characterized by a mixed-phase stratocumulus cloud layer, featuring convective cells with increased liquid water and efficient ice growth in the updrafts (Fig. 4a), which is common for marine Arctic MPCs (Shupe et al. 2008). This stratocumulus cloud structure is substantially altered for both boundary layer perturbation cases. After $20 \mathrm{~h}$ of simulation time, the stratocumulus deck breaks up and transitions to cumulus cloud structures in the W_BL simulation (Fig. 4b) as a result of higher buoyancy, the cloud-top rise, and reduced lateral detrainment at drier layers aloft. This stratocumuluscumulus transition occurs earlier in the case of an additional moisture perturbation in WM_BL (Fig. 4c). Domain mean LWP decreases in both perturbation simulations to around $40 \mathrm{~g} \mathrm{~m}^{-2}$ and the liquid cloud fraction decreases from $100 \%$ to $35 \%$ and $25 \%$ at the end of the simulated period in W_BL and WM_BL, respectively (Figs. 5a,c). Once the cloud deck has started to break up, any recovery is hindered by the stable boundary layer stratification (Fig. 3a) and a lower surface 


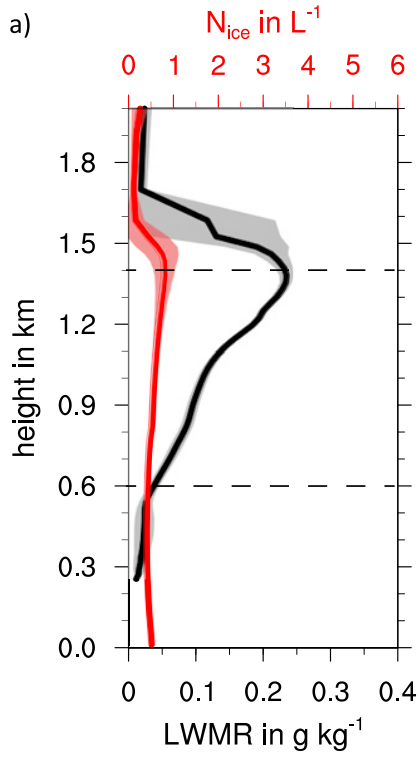

b)
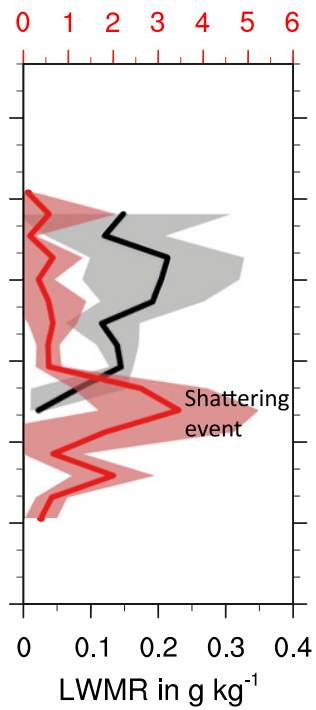

FIG. 2. Domain- and time-averaged $(2-24 \mathrm{~h}) \pm 1$ standard deviation of $N_{\text {ice }}$ (red) and LWMR (black) in the (a) Control simulation and (b) ACCACIA observations over the open ocean (Facility for Airborne Atmospheric Measurements et al. 2015). Only in-cloud values $\left(q_{c}>0.01 \mathrm{~g} \mathrm{~m}\right)^{-3}$ are plotted. The horizontal dashed lines represent the mean modeled cloud top and base $(>1 \%$ of the domain grid points are cloud covered). Note that the high $N_{\text {ice }}$ at $0.7 \mathrm{~km}$ in the observations has been identified by Young et al. (2016) as a shattering event and that the lowermost $0.3 \mathrm{~km}$ were not sampled by the airplane during the campaign.

latent heat flux in the perturbed simulations (Fig. 5i). In the WM_BL simulation, excessive humidity leads to a LWP surge in the first simulated hour and a subsequent surface precipitation increase (Figs. 5a,d).

As a result of the weakened temperature inversion and the cloud-top rise, the ice phase is able to survive the warm air perturbation in the lifted convective cores due to colder temperatures at higher levels ( $253 \mathrm{~K}$ on average) as compared to temperatures at the cloud top in Control (255 K on average; Figs. $5 \mathrm{~g}$ and $5 \mathrm{~h}$ ). The temporal development of IWP is characterized by pronounced peaks, which tend to follow periods of elevated LWP. These alternating LWP/IWP peaks can be understood as a continuous cycle of an increase in LWP with consecutive freezing, which in turn lowers LWP. As a result of elevated levels of cloud ice and the formation of ice and snow crystals, surface precipitation increases. Also, interesting to note is the oscillatory behavior of the cloud-top temperature in the first $12 \mathrm{~h}$ of the Control simulation (Fig. 5h). The 2-hourly cycle of alternating colder and warmer temperatures results from temperature adjustments to the continuous cloud-top rise throughout the first $12 \mathrm{~h}$, subsequent warming resulting from latent heat release during cloud droplet and ice crystal formation, and a following temperature decrease in response to further cloud-top rise and adiabatic expansion. In the perturbed simulations, where the cloud top is initially higher and remains relatively stable, cloud-top temperatures are gradually decreasing.

These modified boundary layer and cloud properties have implications for the energy balance at the surface (Figs. 5e,i,j). The outgoing longwave (LW) radiation is increased and the turbulent surface fluxes from the ocean to the atmosphere are decreased in the perturbation simulations as compared to the Control simulation. The reduced turbulent surface fluxes in addition to the cloud radiative forcing contribute to the strong surface LW cooling; however, the evolution of outgoing LW radiation directly follows the LWP decrease in the perturbed simulations. Hence, we reason that the thinning and break-up of the stratocumulus clouds dominate the LW radiation response and lead to a $\mathrm{LW}$ cooling of up to $95 \mathrm{~W} \mathrm{~m}^{-2}$ in the WM_ $\mathrm{BL}$ simulation. This resembles an increase of outgoing $\mathrm{LW}$ radiation of $60 \%$ compared to the Control simulation and implies a strong surface cooling in the absence of SW radiation. Apart from the cloud radiative forcing, there may additionally be clear-sky effects in which the warm and moist airmass perturbations contribute to stronger LW downwelling radiation. This could partially offset the LW cooling due to the reduced LWP and cloud fraction. Unfortunately, we cannot quantify this effect from our model output, but it is worth noting that the LW cooling due to cloud adjustments may likely be larger that the net LW cooling shown in Fig. 5e.

Overall, the simulated cloud response to the near-surface warm and moist airmass perturbations is consistent with previous studies. Our simulated lifting and weakening of the temperature inversion has previously been noted during intrusions events (Johansson et al. 2017; Messori et al. 2018). In addition, the decrease in cloud fraction and increase in cloudtop height during boundary layer airmass perturbations agree with observations from Knudsen et al. (2018) during warm and moist air intrusions occurring within and above the boundary layer. In contrast, Johansson et al. (2017) find that warm and moist airmass perturbations may increase cloud fraction under dry conditions over multiyear sea ice. Based on our results, we suggest that the surface conditions may be an important driver of the cloud response to airmass perturbations, as for openocean conditions, warm (and moist) airmass perturbations contribute to a boundary layer destabilization, more convection, and lead to a reduction rather than an increase in cloud fraction.

Apart from the surface condition, the height of the airmass perturbation may impact the cloud response. Thus, we discuss warm and moist airmass perturbations occurring in the lower free troposphere in the following.

\section{Stratocumulus response to perturbations in the lower free troposphere}

As shown in Figs. 6 and 7, the stratocumulus cloud structure is maintained for the W_LFT, WM_LFT, and WhM_LFT perturbation simulations, and liquid cloud fractions remain at $100 \%$ throughout the perturbed simulations (Fig. 7c). Resulting from warmer temperatures in and below the inversion layer in the perturbation simulations (Fig. 3b), ice formation is limited, which decreases the IWP and the cloud ice fraction. The reduced IWP in addition to the more stably stratified boundary layer in turn increases LWP (Figs. 7a-c). The increased freetropospheric humidity in the perturbation simulations may in 
TABLE 1. Summary of all experiments performed. Note that the boundary layer is already saturated in Control. Thus, an additional moisture perturbation did not affect our results and the WhM_BL simulation is not included in the analyses.

\begin{tabular}{lcc}
\hline \multicolumn{1}{c}{ Name } & $\begin{array}{c}\text { Boundary layer } \\
\text { profile }\end{array}$ & $\begin{array}{c}\text { Lower-free- } \\
\text { tropospheric profile }\end{array}$ \\
\hline Control & - & - \\
W_BL & Warming (5 K) & - \\
WM_BL & $\begin{array}{c}\text { Warming (5 K), } \\
\text { constant RH }\end{array}$ \\
W_LFT & - & - \\
WM_LFT & - & Warming (5 K) \\
WhM_LFT & - & Warming (5 K), constant RH \\
& & $\left(0.7 \mathrm{~g} \mathrm{~kg}^{-1}\right)$, moistening \\
\hline
\end{tabular}

addition weaken the drying effect through entrainment, as previously shown for warm-phase marine stratocumulus by Ackerman et al. (2004).

The lowered inversion layer also controls the cloud thickness. The stratocumulus cloud top is pushed downward for the case of a warm temperature perturbation (Fig. $7 \mathrm{~g}$ ), but in the presence of additional moist air above the inversion layer the cloud top is substantially higher as compared to Control. However, the cloud top illustrated in Fig. $7 \mathrm{~g}$ represents the top of an upper cloud layer, which forms as a result of a supersaturated free troposphere in the WM_LFT and WhM_LFT simulations.

To further investigate the altered vertical cloud structures in WM_LFT and WhM_LFT, we analyze cross sections of the simulated cloud in more detail. An exemplary cross section at $12 \mathrm{~h}$ (i.e., when the cloud top is highest) and $y=270 \mathrm{~km}$ is shown in Fig. 8. The higher specific humidity above the inversion layer leads to the development of small (mainly icecontaining) cloud structures in WM_LFT and a multilayer mixed-phase stratocumulus cloud in WhM_LFT between 1.5 and $2.8 \mathrm{~km}$. Resulting from a lower temperature inversion, the lower cloud layer is pushed downward to $0.4-1 \mathrm{~km}$ in WhM LFT (Figs. 8 and 7f). The multilayer stratocumulus cloud structure in WhM_LFT has implications for the spatial cloud ice distribution and the total IWP within the MPC. While IWP is initially low in WhM_LFT, the ice phase substantially increases after $10 \mathrm{~h}$ simulation time (Fig. 7b). This increase in IWP thus suggests an additional ice enhancement process at play in the multilayer cloud compared to the Control simulation.

As visualized in Figs. 6a and 8, ice crystals grow efficiently in regions of increased liquid water content (LWC), which coincide with the updraft cores in the Control simulation. Growing ice crystals then fall out as precipitation. In the case of a multilayer cloud, this spatial correlation of cloud liquid and ice reverses. As the coldest temperatures in the upper cloud layer reach down to $250 \mathrm{~K}$ (Fig. $7 \mathrm{~h}$ ), ice forms in the upper cloud layer. Once formed, the ice crystals sediment into the lower cloud, where they deplete cloud droplets as a result of the Wegener-Bergeron-Findeisen (WBF) mechanism (Wegener 1911; Bergeron 1935; Findeisen 1938) or through riming on supercooled liquid droplets. This sequence resembles the seeder-feeder process, where ice particles originating from a "seeder" cloud fall through a lower-level "feeder" cloud (e.g., Rutledge and Hobbs 1983). As a result, IWP is highest in regions of low LWP, which is in contrast to coinciding patches of LWP and IWP in the Control, W_LFT, and WM_LFT simulations (Fig. 6). Once the "seeding" has been initialized, IWP and surface precipitation increase in the WhM_LFT simulation. The increase of precipitation and a depletion of cloud liquid water as a result of the seeder-feeder processes is a common phenomenon in orographic terrain (Choularton and Perry 1986) and Arctic multilayer MPCs (Avramov and Harrington 2010; Oue et al. 2016). Nevertheless, we find that the precipitation increase and the LWP decrease as a result of the seeder-feeder process do not deplete the lower cloud layer completely. In a longer simulation of $48 \mathrm{~h}$ (not shown), cloud fraction decreased, but locally the multilayer cloud structure was maintained.

In terms of the surface energy balance, simulated changes are smaller than for warm perturbations in the boundary layer (Figs. 7e,i,j). Resulting from the generally warmer and moister boundary layer in the perturbation simulations (Fig. 3), the turbulent surface fluxes are decreased relative to the Control simulation. This response is similar to the response simulated for boundary layer airmass perturbations, but weaker in magnitude (Figs. 7i,j). The increased cloud thickness and warmer temperatures of the lower cloud layer increase the cloud emissivity and decrease the outgoing LW radiation at the surface by $10-20 \mathrm{~W} \mathrm{~m}^{-2}$ in the perturbed simulations by the end of the simulated time period (Fig. 7e). The resulting warming in the perturbed simulations is similar for W_LFT and WM_LFT, and even more pronounced for the multilayer cloud in WhM_LFT.

Concluding, warm and moist airmass perturbations in the lower free troposphere maintain the stratocumulus cloud structure. For both warm only and warm and moist anomalies, the temperature inversion strengthens and subsides, and the underlying cloud top and base of the boundary layer cloud shift to lower altitudes. These changes are similar to the simulated subtropical boundary layer cloud response to increased inversion strength by Bretherton et al. (2013). The simulated cloud and temperature inversion adjustments as well as the net LW surface warming during moist airmass perturbations in the lower free troposphere also agree with observations from Tjernström et al. (2015, 2019) and Persson et al. (2017).

Additionally, we find that in the case of warm and moist airmass perturbations the cloud liquid water is distributed among two cloud layers. This presence of a multilayer cloud and increased IWP during warm and moist airmass perturbations in the lower free troposphere differs substantially from our simulated cloud changes during boundary layer airmass perturbations and observations from Knudsen et al. (2018), where temperature and moisture anomalies were mainly prominent within and above the atmospheric boundary layer.

\section{Linking inversion strength to cloud properties}

Sections 4 and 5 demonstrated a strong impact of the inversion strength on the simulated cloud properties. Previous 
a) Initial boundary layer perturbation
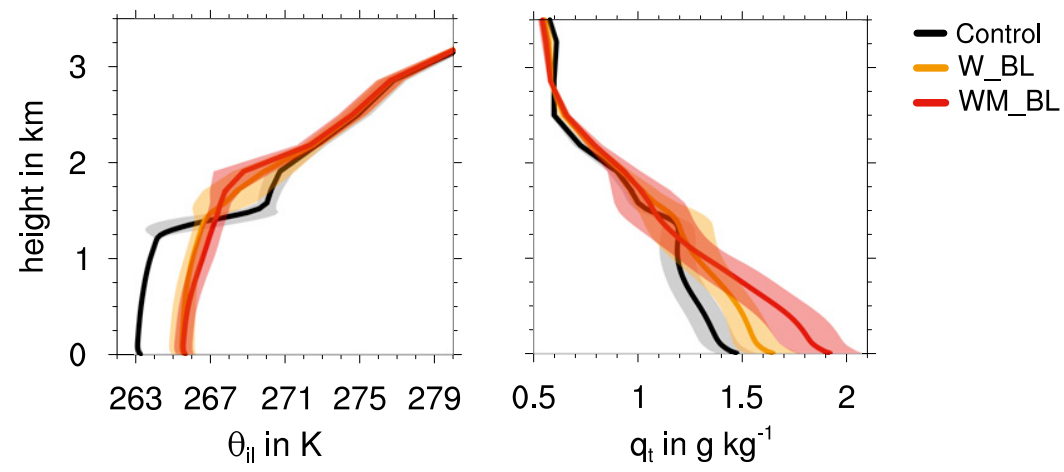

\section{b) Initial perturbation in the lower free troposphere}
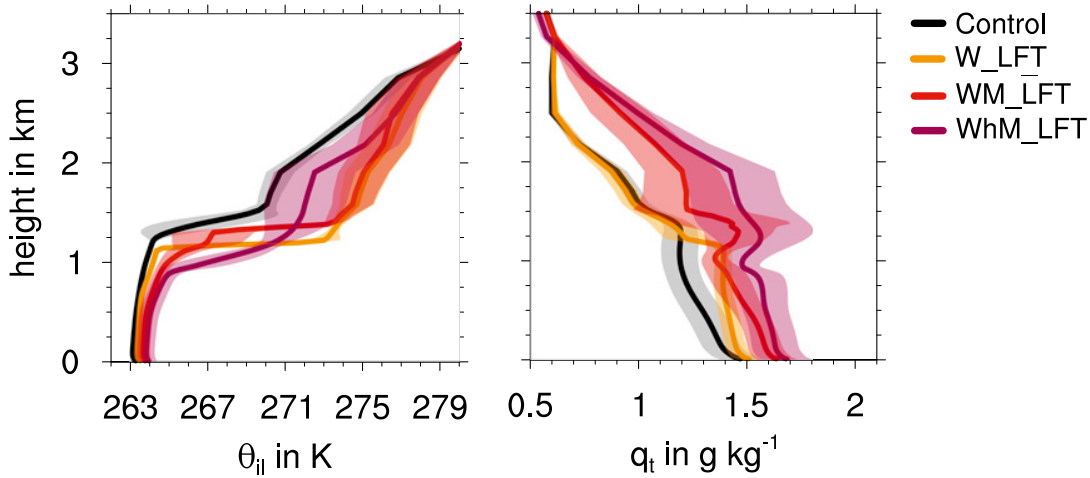

FIG. 3. Time- and domain-averaged ( \pm 1 temporal and spatial standard deviation) iceliquid potential temperature $\left(\theta_{\mathrm{il}}\right)$ and total water content $q_{t}=q_{c}+q_{v}+q_{i}$, where $q_{c}$ is the cloud water content and $q_{i}$ the ice water content. Shown are (a) profiles for all simulations resembling an initial boundary layer perturbation and (b) an initial perturbation in the lower free troposphere.

work established a positive correlation between regional stratiform cloud fraction and inversion strength or lowertropospheric stability (LTS) on seasonal time scales (Klein and Hartmann 1993). Following Klein and Hartmann (1993), we examine the sensitivity of boundary layer cloud properties to LTS after $24 \mathrm{~h}$ of simulation time (Fig. 9). As our simulated cloud fractions after $24 \mathrm{~h}$ are always $100 \%$ for the Control and the LFT simulations, and $35 \%$ and $25 \%$ for W_BL and WM_ BL, respectively, we do not find such a relationship for cloud fraction in our simulations. Instead, we find that LWP and the total water path (TWP $=$ LWP + IWP) scale with LTS (Figs. 9a,b). Our definition of inversion strength follows Medeiros et al. (2011), by defining the inversion strength as the difference in potential temperatures above the inversion and near the surface: $\Delta \theta=\theta_{\mathrm{atm}}-\theta_{\mathrm{sfc}}$. The 750 -hPa pressure level (corresponding to $2.2-\mathrm{km}$ altitude) is chosen as the upper level, which fits our initial profiles. To compare the same cloud layers, we included LWP and TWP only from the boundary layer clouds (in the case of WM_LFT and WhM_LFT).

For our simulated cases representing boundary layer airmass perturbations, LTS and thus the temperature inversion weakens, which favors convection and increases surface precipitation (Fig. 9c). As a result, LWP and TWP decrease for low LTS (Figs. 9a,b). If warm and moist airmass perturbations occur in the lower free troposphere, LTS increases and the inversion persists and strengthens. Resulting from relatively lower surface precipitation rates, LWP and TWP are increased for high LTS as compared to the boundary layer perturbation cases (Fig. 9).

Our results of a linear relationship between LWP and LTS differ from the results of Wood and Hartmann (2005), where the cloud mean LWP and LTS were generally uncorrelated, except for a small region in the southeast Pacific. These different findings indicate that the spatial and temporal scales of variability are important for establishing correlations between meteorological drivers and low-level cloud properties. On daily to weekly time scales and larger regional scales such as investigated by Wood and Hartmann (2005), LWP and LTS seem to show a lower degree of correlation. However, on subdaily time scales and spatially more confined regions such as simulated for our case study, LTS may be an important driver of low-level stratocumulus LWP. 

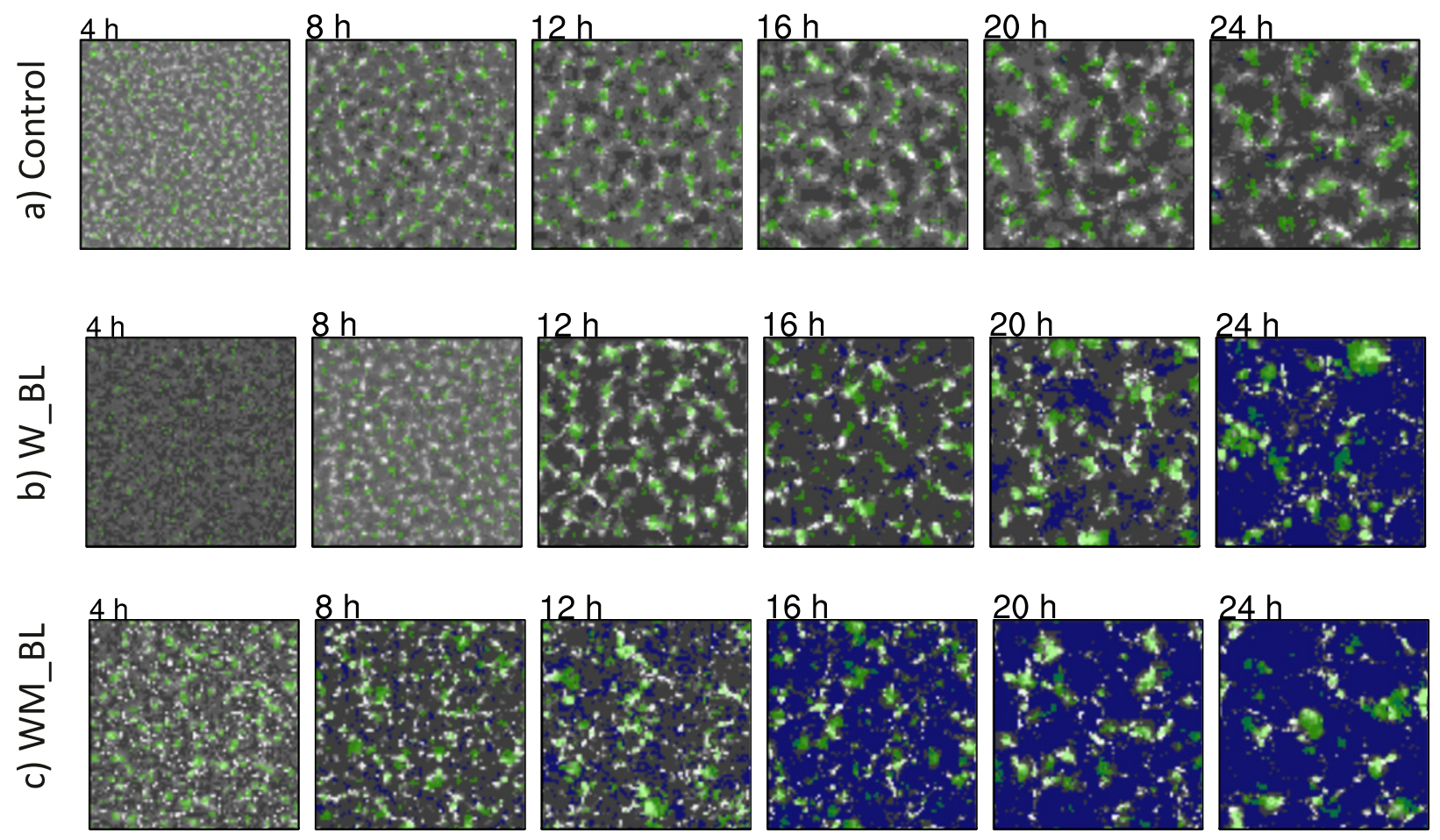

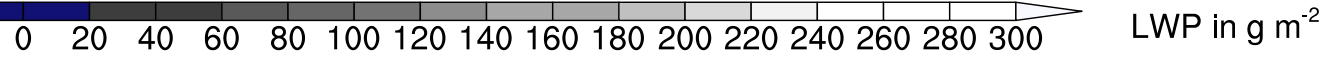

FIG. 4. Temporal snapshots of LWP (colors) and IWP exceeding the 85th percentile of the spatial IWP distribution (green) for the (a) Control, (b) W_BL, and (c) WM_BL simulations.

\section{Discussion and conclusions}

In this study we investigated the potential impact of warm and moist air perturbations on Arctic low-level mixed-phase stratocumulus in a semi-idealized modeling case study during the ACCACIA campaign in March 2013. To differentiate between the cloud response to airmass perturbations observed during previous field campaigns, we performed a series of simulations where the perturbation height as well as the perturbation temperature and moisture were varied among individual experiments. Our applied initial perturbations represent
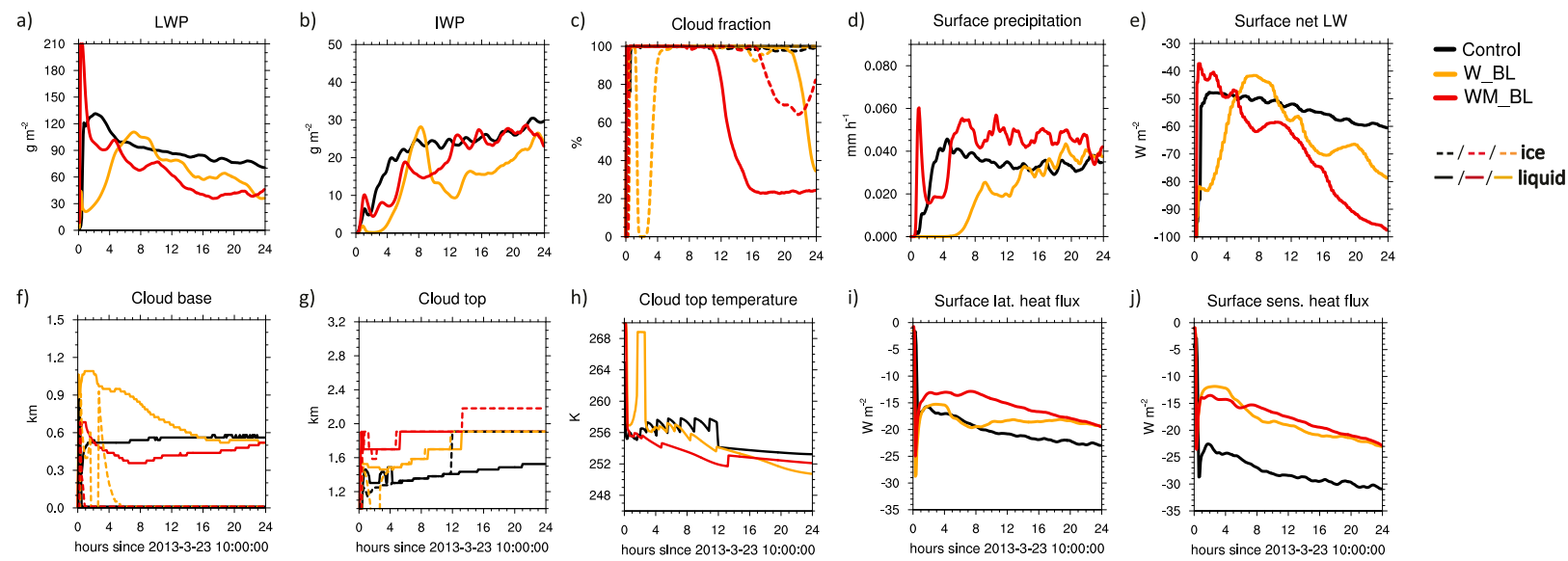

FIG. 5. Evolution of (a) LWP, (b) IWP, (c) cloud fraction for the liquid and ice phase, (d) total surface precipitation, (e) outgoing LW radiation, (f) cloud base for the liquid and ice phase (note that cloud ice reaches the surface, such that the ice cloud base is at $0 \mathrm{~km}$ ), (g) cloud top for the liquid and ice phase, (h) mean temperature at the level of the ice cloud top, (i) surface latent heat flux, and (j) surface sensible heat flux in the Control, W_BL, and WM_BL simulations. The surface sensible and latent heat fluxes are defined positive downward. 

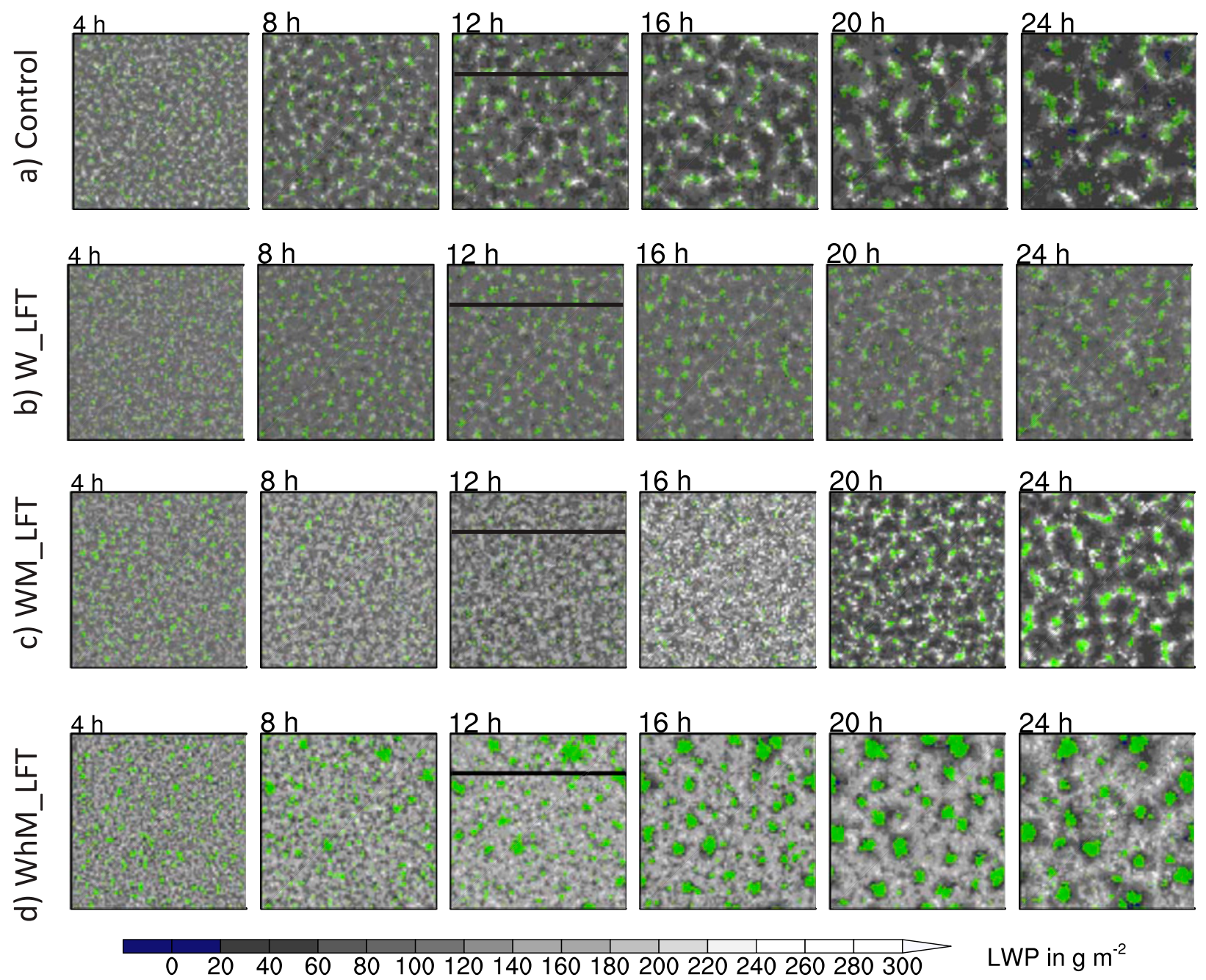

FIG. 6. As in Fig. 4, but for airmass perturbations in the lower free troposphere and additionally the WhM_LFT simulation. The black bars at $12 \mathrm{~h}$ denote the cross section shown in Fig. 8.

local airmass changes which could be generated by airmass intrusions.

Most previous case studies (Tjernström et al. 2015, 2019; Persson et al. 2017) focused on the impact of airmass intrusions on cloud properties over sea ice, where the impact of airmass intrusions on cloud fraction has been found to be strongest (Johansson et al. 2017), likely due to the generally drier boundary layer over sea ice surfaces (e.g., Young et al. 2016). In this work, we focused on the cloud response to airmass perturbation such as could be expected from airmass intrusions over the open ocean. We show that some previous findings can be generalized to different surface conditions, while other elements of the cloud response might be unique to the openocean environment. The main findings of our study are summarized in the schematic shown in Fig. 10. Our findings are separated by perturbation height, which strongly affects the cloud response.

Despite the already moist and turbulent tropospheric conditions over the open ocean as opposed to sea ice-covered surfaces, warm and moist airmass perturbations close to the surface destabilize and deepen the boundary layer (Fig. 10b). As a result, the stratocumulus deck breaks up, the cloud top is lifted, and cloud fraction decreases from $100 \%$ to $25 \%$. The reduced cloud fraction and the lower LWP increase the amount of outgoing LW radiation, which results in substantial surface cooling of $95 \mathrm{~W} \mathrm{~m}^{-2}$ in the absence of solar radiation (i.e., during polar winter). These findings agree well with findings from Knudsen et al. (2018), who observed warm and moist air intrusions occurring within and above the boundary layer at the sea ice edge. Similarly, the increased development of convective structures under the destabilizing conditions of a warming ocean surface has also been simulated by Young et al. (2018). Considering the possibility of an ice-free Arctic by midcentury (Overland and Wang 2013), our simulated stratocumulus break-up and LW cooling under boundary layer airmass perturbations may become representative for the effect of warm air intrusions in a future Arctic climate. 

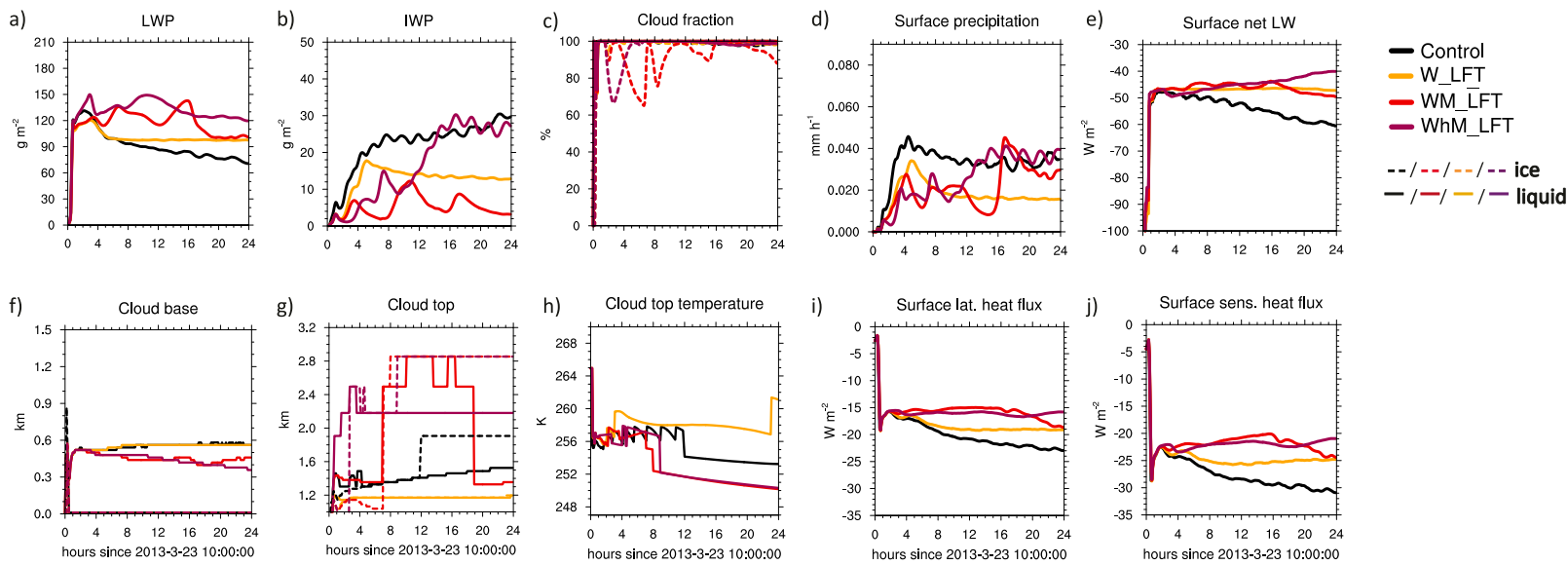

FIG. 7. As in Fig. 5, but for airmass perturbations in the lower free troposphere and additionally the WhM_LFT simulation.

A very different response of the cloud layer is simulated for airmass perturbations in the lower free troposphere (Figs. 10c-e). LWP increases and the cloud fraction remains high throughout the simulation. In simulations of increased specific humidity within the warm and moist airmass perturbation in the lower free troposphere, multilayer clouds form. Inside the upper-level cloud layer, ice forms efficiently at the colder temperatures aloft (250$252 \mathrm{~K}$ ). These newly formed ice crystals sediment and locally deplete liquid water in the underlying cloud according to the "seeder-feeder" process. This increase in ice mass leads to an intensification of surface precipitation after $12 \mathrm{~h}$ of simulation time. As a result of the simulated thicker cloud, the outgoing LW radiation is reduced, which induces a surface warming rate of 10$20 \mathrm{~W} \mathrm{~m}^{-2}$ by the end of the simulated time period. This response in consistent with observed cloud adjustments to airmass intrusions over sea ice (Tjernström et al. 2015, 2019; Persson et al. 2017) and highlights the importance of moisture sources at cloud top in the Arctic (Solomon et al. 2011, 2014; Loewe et al. 2017).

Our work confirms the relevance of airmass characteristics for boundary layer cloud formation and evolution. However, apart from airmass perturbations, other relevant environmental factors might impact cloud properties and/or the cloud
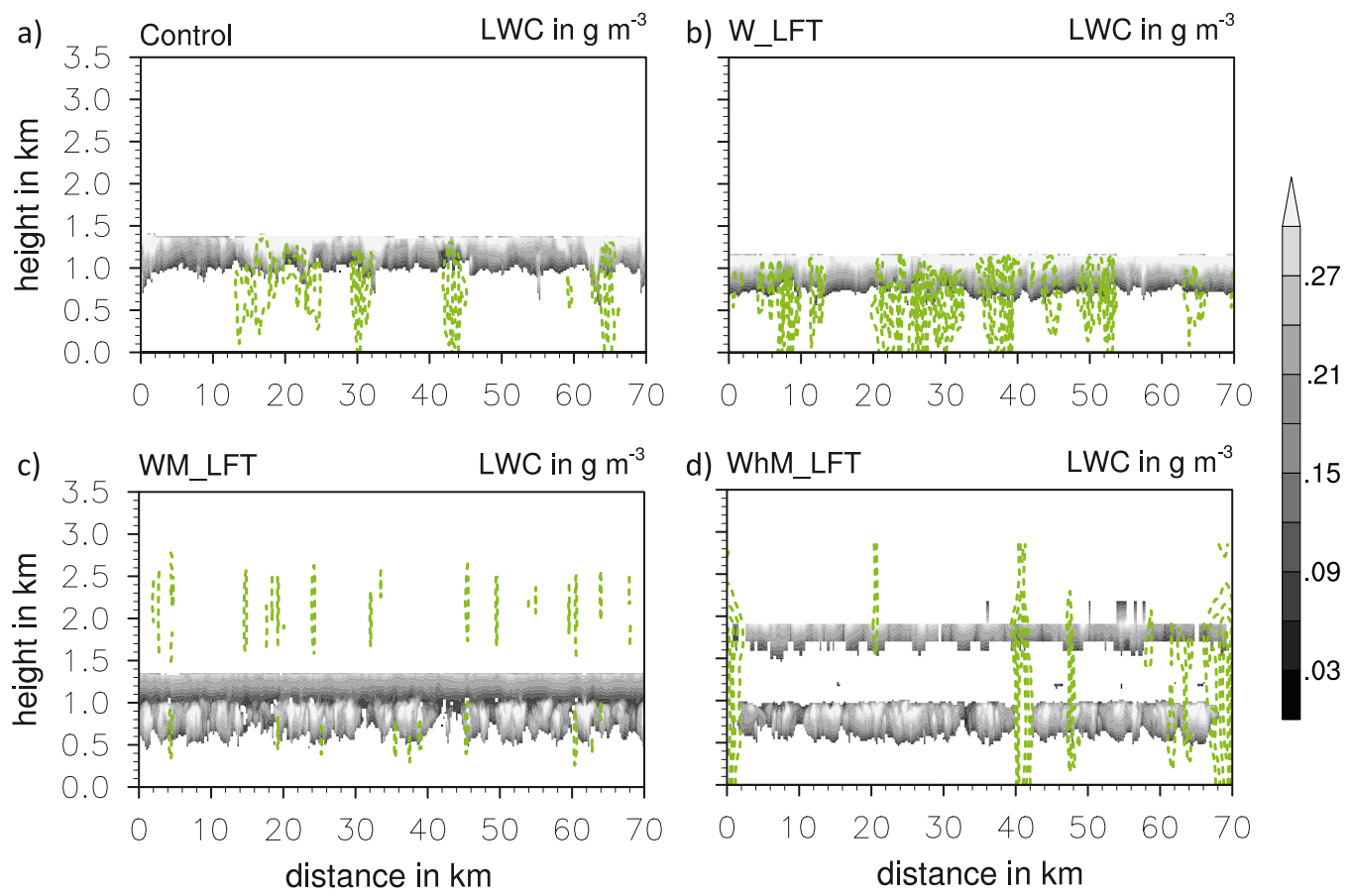

FIG. 8. Cross section at $12-\mathrm{h}$ simulation time at $y=270 \mathrm{~km}$ for the (a) Control and (b)-(d) all LFT perturbation simulations. Colors represent LWC; green contours for IWC are plotted in $0.05 \mathrm{~g} \mathrm{~m}^{-3}$ intervals for the Control simulation and in $0.02 \mathrm{~g} \mathrm{~m}^{-3}$ intervals for the perturbation simulations (due to lower overall IWP). 

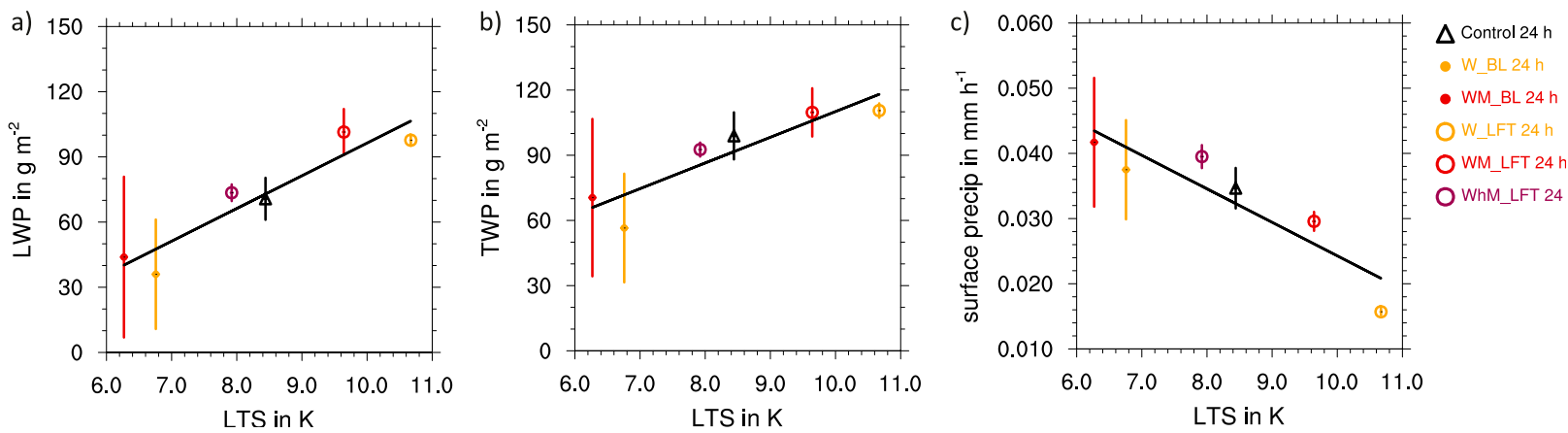

FIG. 9. Scatterplot of mean inversion strength $\left(\Delta \theta=\theta_{\mathrm{atm}}-\theta_{\mathrm{sfc}}\right)$ and (a) LWP, (b) TWP, and (c) surface precipitation rate at 24-h simulation time in all simulations. The bars represent \pm 1 standard deviation. For the LFT perturbation simulations, only the LWP and TWP within the boundary layer were included. The black lines denote the linear regressions.

response to airmass changes. In this regard, airmass intrusions can also go hand in hand with altered ambient aerosol concentrations through the advection of additional CCN or INPs (Pithan et al. 2018). We did not investigate the aerosol effect in this study, but we suspect that aerosol changes could act in conjunction with the dynamically driven cloud response to airmass perturbations. As an increase in background INPs or a decrease in $\mathrm{CCN}$ have been found to lead to a stratocumulus break-up into cumulus structures through changes in cloud organization (Eirund et al. 2019a), additional INPs or fewer $\mathrm{CCN}$ could strength the effect of boundary layer airmass changes. Meanwhile, increases in $\mathrm{CCN}$ have also been shown to thicken the cloud deck (Morrison et al. 2008; Possner et al. 2017; Stevens et al. 2018; Solomon et al. 2018; Eirund et al. 2019 b) and could mitigate the effect of boundary layer airmass perturbations.

Airmass intrusions can also be accompanied by subsidence changes (Neggers et al. 2019; Tjernström et al. 2019). An increase in large-scale subsidence can have a similar effect as our modeled perturbations in the lower free troposphere by strengthening the inversion and increasing LWP and IWP (Young et al. 2018). However, sudden changes in subsidence can push the boundary layer top below the lifting condensation level and initiate cloud dissipation (Neggers et al. 2019). a)

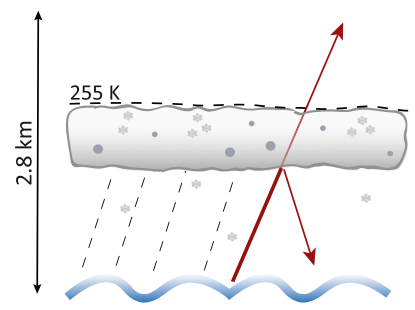

b) Boundary layer: warm (and moist) perturbation
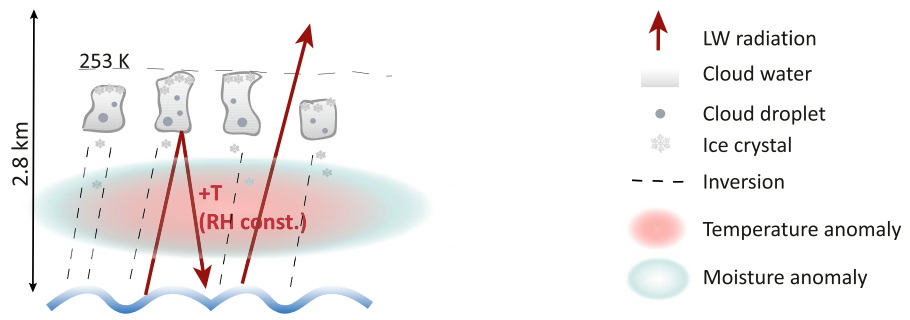

e) Warm and additionally moist perturbation

c) Lower free troposphere: warm perturbation

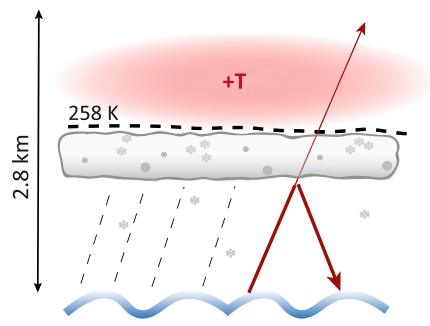

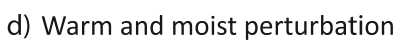

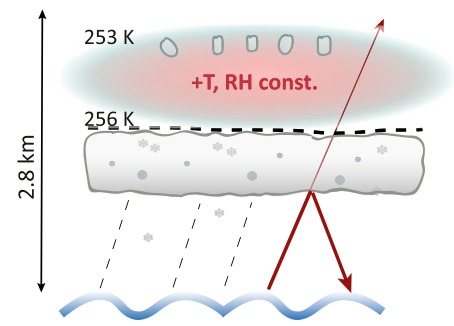

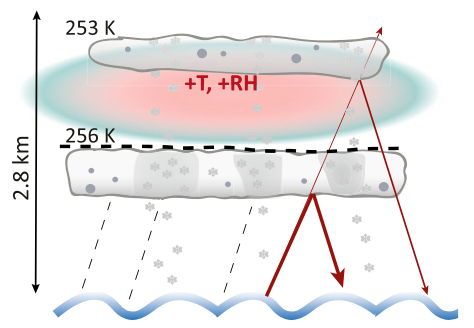

FIG. 10. Schematic summary of the cloud response to (a) no perturbation (Control state), (b) boundary layer airmass perturbations (similar for warm perturbations only and warm and moist air perturbations), and (c)-(e) airmass perturbations in the lower free troposphere. The red and green shadings represent the locations of the temperature and moisture perturbations. Gray shadings represent the cloud LWP, with darker regions in (e) denoting lower LWC. The red arrows show LW radiation. The black dashed lines denote the capping inversions; thicker lines represent a stronger inversion. The numbers indicate the cloud-top temperatures. 
Last, entrainment processes especially at cloud top could be crucial for cloud moistening or drying (Ackerman et al. 2004). To properly simulate cloud-top entrainment, much finer vertical resolutions than used in our study are required. Thus, with a refined vertical resolution throughout the boundary layer and the lower free troposphere, the effect of airmass perturbations could be quantified more accurately. However, for analyzing microscale cloud processes, compromises regarding the domain size had to be condoned.

In summary, we can infer the following three key conclusions from the perturbation experiments conducted in this study:

- Our findings suggest the perturbation height to be a crucial factor controlling the boundary layer stability and low-level cloud response to airmass perturbations. Contrasting findings regarding cloud changes in response to airmass intrusions from a variety of field campaigns may partly be explained by different vertical structures of the warming and moistening associated with the airmass intrusion.

- While most previous case studies were conducted over sea ice, we show that also over the open ocean where the boundary layer is usually moister and more turbulent, airmass perturbations substantially affect stratocumulus cloud properties. For boundary layer airmass perturbations, increased convective activity is modeled and cumulus formation is enhanced. Warm and moist anomalies in the lower free troposphere thicken the cloud layer, as also observed for airmass intrusions over sea ice.

- Inversion height and strength have been found to be key predictors for regional low-level cloud properties on subdaily time scales. This importance of the inversion layer underlines the relevance of a realistic representation of the thermodynamic boundary layer profiles when simulating low-level stratocumulus.

Using these perturbation experiments we gained first insights into the generalization of observed phenomena regarding airmass intrusions over sea ice to open-ocean conditions north of the Arctic circle. However, our approach remains limited as we cannot follow the cloud evolution capturing the airmass history in full. Utilizing Lagrangian model frameworks following the airmass history from the open ocean and over the sea ice can further help generalize our understanding of the impact of moist and warm air intrusions on Arctic boundary layers.

Acknowledgments. AP is receiving support from MOPGAGRI (57429624), which is funded by the BMBF and implemented by the DAAD. All simulations were performed with the Consortium for Small-scale Modeling (COSMO) model adapted for large eddy simulations. The simulations were performed at the Swiss National Supercomputing Center (CSCS). The authors wish to thank Paul Field for his comments on an early version of this study and the three anonymous reviewers for their constructive feedback that substantially improved the manuscript.

Data availability statement. The model output used for our analysis is available at http://doi.org/10.5281/zenodo.3699108 (Eirund et al. 2020). Observations from the ACCACIA cam- paign were obtained from the NCAS British Atmospheric Data Centre (Facility for Airborne Atmospheric Measurements et al. 2015).

\section{REFERENCES}

Ackerman, A. S., M. P. Kirkpatrick, D. E. Stevens, and O. B. Toon, 2004: The impact of humidity above stratiform clouds on indirect aerosol climate forcing. Nature, 432, 1014-1017, https:// doi.org/10.1038/nature03174.

Alexeev, V. A., P. L. Langen, and J. R. Bates, 2005: Polar amplification of surface warming on an aquaplanet in "ghost forcing" experiments without sea ice feedbacks. Climate Dyn., 24, 655-666, https://doi.org/10.1007/s00382-005-0018-3.

Alraddawi, D., and Coauthors, 2018: Comparison of total water vapour content in the Arctic derived from GNSS, AIRS, MODIS and SCIAMACHY. Atmos. Meas. Tech., 11, 29492965, https://doi.org/10.5194/amt-11-2949-2018.

Avramov, A., and J. Y. Harrington, 2010: Influence of parameterized ice habit on simulated mixed phase Arctic clouds. J. Geophys. Res., 115, D03205, https://doi.org/10.1029/2009JD012108.

Bennartz, R., and Coauthors, 2013: July 2012 Greenland melt extent enhanced by low-level liquid clouds. Nature, 496, 83-86, https://doi.org/10.1038/nature12002.

Bergeron, T., 1935: On the physics of clouds and precipitation. Proc. Fifth General Assembly of the International Geodetic Geophysical Union, Lisbon, Portugal, 156-178.

Bretherton, C. S., P. N. Blossey, and C. R. Jones, 2013: Mechanisms of marine low cloud sensitivity to idealized climate perturbations: A single-LES exploration extending the CGILS cases. J. Adv. Model. Earth Syst., 5, 316-337, https://doi.org/10.1002/jame.20019.

Chernokulsky, A. V., I. Esau, O. N. Bulygina, R. Davy, I. I. Mokhov, S. Outten, and V. A. Semenov, 2017: Climatology and interannual variability of cloudiness in the Atlantic Arctic from surface observations since the late nineteenth century. J. Climate, 30, 2103-2120, https://doi.org/10.1175/JCLI-D-160329.1.

Choularton, T. W., and S. J. Perry, 1986: A model of the orographic enhancement of snowfall by the seeder-feeder mechanism. Quart. J. Roy. Meteor. Soc., 112, 335-345, https://doi.org/ 10.1002/qj.49711247204.

Cohen, J., and Coauthors, 2014: Recent Arctic amplification and extreme mid-latitude weather. Nat. Geosci., 7, 627-637, https:// doi.org/10.1038/ngeo2234.

Curry, J. A., J. Schramm, and E. E. Ebert, 1995: Sea ice-albedo climate feedback mechanism. J. Climate, 8, 240-247, https:// doi.org/10.1175/1520-0442(1995)008<0240:SIACFM>2.0.CO;2.

_- W. B. Rossow, D. Randall, and J. Schramm, 1996: Overview of Arctic cloud and radiation characteristics. J. Climate, $\mathbf{9}$, 1731-1764, https://doi.org/10.1175/1520-0442(1996)009<1731: OOACAR $>2.0 . \mathrm{CO} ; 2$.

Dahlke, S., and M. Maturilli, 2017: Contribution of atmospheric advection to the amplified winter warming in the Arctic North Atlantic region. Adv. Meteor., 2017, 1-8, https://doi.org/ 10.1155/2017/4928620.

DeMott, P. J., A. J. Prenni, G. R. McMeeking, and A. Others, 2015: Integrating laboratory and field data to quantify the immersion freezing ice nucleation activity of mineral dust particles. Atmos. Chem. Phys., 15, 393-409, https://doi.org/10.5194/acp-15-393-2015.

Eirund, G. K., U. Lohmann, and A. Possner, 2019a: Cloud ice processes enhance spatial scales of organization in Arctic stratocumulus. Geophys. Res. Lett., 46, 14 109-14117, https:// doi.org/10.1029/2019GL084959. 
- A. Possner, and U. Lohmann, 2019b: Response of Arctic mixed-phase clouds to aerosol perturbations under different surface forcings. Atmos. Chem. Phys., 19, 9847-9864, https:// doi.org/10.5194/acp-19-9847-2019.

— _ _ and _ 2020: Data for the publication 'The impact of warm and moist air mass intrusions on Arctic mixed-phase stratocumulus.' Zenodo, https://doi.org/10.5281/zenodo.3699109.

Facility for Airborne Atmospheric Measurements and Coauthors, 2015: FAAM B762 ACCACIA flight, number 4: Airborne atmospheric measurements from core and non-core instrument suites on board the BAE-146 aircraft. NCAS British Atmospheric Data Centre, accessed 6 June 2020, https:// catalogue.ceda.ac.uk/uuid/88f95b1d52804b27882fbb798b116d3a.

Findeisen, W., 1938: Kolloid-meteorologische Vorgänge bei Neiderschlags-bildung. Meteor. Z., 55, 121-133.

Gilgen, A., W. T. K. Huang, L. Ickes, D. Neubauer, and U. Lohmann, 2018: How important are future marine and shipping aerosol emissions in a warming Arctic summer and autumn? Atmos. Chem. Phys., 18, 10 521-10 555, https:// doi.org/10.5194/acp-18-10521-2018.

Graversen, R. G., and M. Wang, 2009: Polar amplification in a coupled climate model with locked albedo. Climate Dyn., 33, 629-643, https://doi.org/10.1007/s00382-009-0535-6.

Hallett, J., and S. C. Mossop, 1974: Production of secondary ice particles during the riming process. Nature, 249, 26-28, https:// doi.org/10.1038/249026a0.

Johansson, E., A. Devasthale, M. Tjernström, A. M. Ekman, and T. L'Ecuyer, 2017: Response of the lower troposphere to moisture intrusions into the Arctic. Geophys. Res. Lett., 44, 2527-2536, https://doi.org/10.1002/2017GL072687.

Kapsch, M.-L., R. G. Graversen, and M. Tjernström, 2013: Springtime atmospheric energy transport and the control of Arctic summer sea-ice extent. Nat. Climate Change, 3, 744748, https://doi.org/10.1038/nclimate1884.

— 2019: Summers with low Arctic sea ice linked to persistence of spring atmospheric circulation patterns. Climate Dyn., 52, 2497-2512, https://doi.org/10.1007/s00382-018-4279-z.

Kay, J. E., M. M. Holland, C. M. Bitz, E. Blanchard-Wrigglesworth, A. Gettelman, A. Conley, and D. Bailey, 2012: The influence of local feedbacks and northward heat transport on the equilibrium Arctic climate response to increased greenhouse gas forcing. J. Climate, 25, 5433-5450, https://doi.org/10.1175/ JCLI-D-11-00622.1.

Klein, S. A., and D. L. Hartmann, 1993: The seasonal cycle of low stratiform clouds. J. Climate, 6, 1587-1606, https://doi.org/ 10.1175/1520-0442(1993)006<1587:TSCOLS $>2.0$.CO;2.

Knudsen, E. M., and Coauthors, 2018: Meteorological conditions during the ACLOUD/PASCAL field campaign near Svalbard in early summer 2017. Atmos. Chem. Phys., 18, 17 995-18 022, https://doi.org/10.5194/acp-18-17995-2018.

Langhans, W., J. Schmidli, and B. Szintai, 2012: A SmagorinskyLilly turbulence closure for COSMO-LES: Implementation and comparison to ARPS. COSMO Newsletter, No. 12, Consortium for Small-Scale Modeling, Offenbach, Germany, 20-31.

Liu, Y., J. R. Key, Z. Liu, X. Wang, and S. J. Vavrus, 2012: A cloudier Arctic expected with diminishing sea ice. Geophys. Res. Lett., 39, L05705, https://doi.org/10.1029/2012GL051251.

,,-- S. Vavrus, and C. Woods, 2018: Time evolution of the cloud response to moisture intrusions into the Arctic during winter. J. Climate, 31, 9389-9405, https://doi.org/10.1175/JCLI-D-17-0896.1.

Lloyd, G., and Coauthors, 2015: Observations and comparisons of cloud microphysical properties in spring and summertime
Arctic stratocumulus clouds during the ACCACIA campaign. Atmos. Chem. Phys., 15, 3719-3737, https://doi.org/10.5194/ acp-15-3719-2015.

Loewe, K., A. M. L. Ekman, M. Paukert, J. Sedlar, M. Tjernström, and C. Hoose, 2017: Modelling micro- and macrophysical contributors to the dissipation of an Arctic mixed-phase cloud during the Arctic Summer Cloud Ocean Study (ASCOS). Atmos. Chem. Phys., 17, 6693-6704, https://doi.org/10.5194/ acp-17-6693-2017.

Medeiros, B., C. Deser, R. A. Tomas, and J. E. Kay, 2011: Arctic inversion strength in climate models. J. Climate, 24, 47334740, https://doi.org/10.1175/2011JCLI3968.1.

Messori, G., C. Woods, and R. Caballero, 2018: On the drivers of wintertime temperature extremes in the high Arctic. J. Climate, 31, 1597-1618, https://doi.org/10.1175/JCLI-D-17-0386.1.

Morrison, A. L., J. E. Kay, H. Chepfer, R. Guzman, and V. Yettella, 2018: Isolating the liquid cloud response to recent Arctic sea ice variability using spaceborne lidar observations. J. Geophys. Res. Atmos., 123, 473-490, https://doi.org/10.1002/ 2017JD027248.

Morrison, H., J. O. Pinto, J. A. Curry, and G. M. McFarquhar, 2008: Sensitivity of modeled Arctic mixed-phase stratocumulus to cloud condensation and ice nuclei over regionally varying surface conditions. J. Geophys. Res., 113, D05203, https:// doi.org/10.1029/2007JD008729.

— , G. de Boer, G. Feingold, J. Harrington, M. D. Shupe, and K. Sulia, 2012: Resilience of persistent Arctic mixed-phase clouds. Nat. Geosci., 5, 11-17, https://doi.org/10.1038/ngeo1332.

Mortin, J., G. Svensson, R. G. Graversen, M. L. Kapsch, J. C. Stroeve, and L. N. Boisvert, 2016: Melt onset over Arctic sea ice controlled by atmospheric moisture transport. Geophys. Res. Lett., 43, 6636-6642, https://doi.org/10.1002/2016GL069330.

Neggers, R. A. J., J. Chylik, U. Egerer, H. Griesche, V. Schemann, P. Seifert, H. Siebert, and A. Macke, 2019: Local and remote controls on Arctic mixed-layer evolution. J. Adv. Model. Earth Syst., 11, 2214-2237, https://doi.org/10.1029/2019MS001671.

Nenes, A., and J. H. Seinfeld, 2003: Parameterization of cloud droplet formation in global climate models. J. Geophys. Res., 108, 4415, https://doi.org/10.1029/2002JD002911.

Oue, M., M. Galletti, J. Verlinde, A. Ryzhkov, and Y. Lu, 2016: Use of X-band differential reflectivity measurements to study shallow Arctic mixed-phase clouds. J. Appl. Meteor. Climatol., 55, 403-424, https://doi.org/10.1175/JAMC-D-15-0168.1.

Overland, J. E., and M. Wang, 2013: When will the summer Arctic be nearly sea ice free? Geophys. Res. Lett., 40, 2097-2101, https://doi.org/10.1002/grl.50316.

Palm, S. P., S. T. Strey, J. Spinhirne, and T. Markus, 2010: Influence of Arctic sea ice extent on polar cloud fraction and vertical structure and implications for regional climate. J. Geophys. Res., 115, D21209, https://doi.org/10.1029/2010JD013900.

Persson, P. O. G., M. D. Shupe, D. Perovich, and A. Solomon, 2017: Linking atmospheric synoptic transport, cloud phase, surface energy fluxes, and sea-ice growth: Observations of midwinter SHEBA conditions. Climate Dyn., 49, 1341-1364, https:// doi.org/10.1007/s00382-016-3383-1.

Pithan, F., and T. Mauritsen, 2014: Arctic amplification dominated by temperature feedbacks in contemporary climate models. Nat. Geosci., 7, 181-184, https://doi.org/10.1038/NGEO2071.

_ , and Coauthors, 2018: Role of air-mass transformations in exchange between the Arctic and mid-latitudes. Nat. Geosci., 11, 805-812, https://doi.org/10.1038/s41561-018-0234-1.

Possner, A., A. M. Ekman, and U. Lohmann, 2017: Cloud response and feedback processes in stratiform mixed-phase clouds 
perturbed by ship exhaust. Geophys. Res. Lett., 44, 1964-1972, https://doi.org/10.1002/2016GL071358.

Ralph, F. M., P. J. Neiman, and R. Rotunno, 2005: Dropsonde observations in low-level jets over the northeastern Pacific Ocean from CALJET-1998 and PACJET-2001: Mean verticalprofile and atmospheric-river characteristics. Mon. Wea. Rev., 133, 889-910, https://doi.org/10.1175/MWR2896.1.

Raschendorfer, M., 2001: The new turbulence parameterization of LM. COSMO Newsletter, No. 1, Consortium for Small-Scale Modeling, Offenbach, Germany, 89-97, http://www.cosmomodel.org/content/model/documentation/newsLetters/newsLetter01/ newsLetter_01.pdf.

Ritter, B., and J.-F. Geleyn, 1992: A comprehensive radiation scheme for numerical weather prediction models with potential applications in climate simulations. Mon. Wea. Rev., 120, 303-325, https://doi.org/10.1175/1520-0493(1992)120<0303: ACRSFN $>2.0 . \mathrm{CO} ; 2$.

Rutledge, S. A., and P. V. Hobbs, 1983: The mesoscale and microscale structure and organization of clouds and precipitation in midlatitude cyclones. VIII: A model for the "seederfeeder" process in warm-frontal rainbands. J. Atmos. Sci., 40, 1185-1206, https://doi.org/10.1175/1520-0469(1983)040<1185: TMAMSA $>2.0 . \mathrm{CO} ; 2$.

Schättler, U., G. Doms, and J. Steppele, 2000: Requirements and problems in parallel model development at DWD. Sci. Program., 8, 13-22, https://doi.org/10.1155/2000/609351.

Schweiger, A. J., R. W. Lindsay, S. Vavrus, and J. A. Francis, 2008: Relationships between Arctic sea ice and clouds during autumn. J. Climate, 21, 4799-4810, https://doi.org/10.1175/2008JCLI2156.1.

Screen, J. A., and I. Simmonds, 2010: Increasing fall-winter energy loss from the Arctic Ocean and its role in Arctic temperature amplification. Geophys. Res. Lett., 37, L16707, https://doi.org/ 10.1029/2010GL044136.

Seifert, A., and K. D. Beheng, 2006: A two-moment cloud microphysics parameterization for mixed-phase clouds. Part 1: Model description. Meteor. Atmos. Phys., 92, 45-66, https:// doi.org/10.1007/s00703-005-0112-4.

Semmler, T., T. Jung, and S. Serrar, 2016: Fast atmospheric response to a sudden thinning of Arctic sea ice. Climate Dyn., 46, 1015-1025, https://doi.org/10.1007/s00382-015-2629-7.

Serreze, M. C., and R. G. Barry, 2011: Processes and impacts of Arctic amplification: A research synthesis. Global Planet. Change, 77, 85-96, https://doi.org/10.1016/j.gloplacha.2011.03.004.

— A. P. Barrett, and J. Stroeve, 2012: Recent changes in tropospheric water vapor over the Arctic as assessed from radiosondes and atmospheric reanalyses. J. Geophys. Res., 117, D10104, https://doi.org/10.1029/2011JD017421.

Shupe, M. D., 2011: Clouds at Arctic atmospheric observatories. Part II: Thermodynamic phase characteristics. J. Appl. Meteor. Climatol., 50, 645-661, https://doi.org/10.1175/2010JAMC2468.1.

— Amer. Meteor. Soc., 89, 1549-1562, https://doi.org/10.1175/ 2008BAMS2378.1.

Solomon, A., M. D. Shupe, P. O. Persson, and H. Morrison, 2011: Moisture and dynamical interactions maintaining decoupled Arctic mixed-phase stratocumulus in the presence of a humidity inversion. Atmos. Chem. Phys., 11, 10127-10148, https://doi.org/10.5194/acp-11-10127-2011.

,,,,---- T. Yamaguchi, P. M. Caldwell, and G. de Boer, 2014: The sensitivity of springtime Arctic mixed-phase stratocumulus clouds to surface-layer and cloud-top inversionlayer moisture sources. J. Atmos. Sci., 71, 574-595, https:// doi.org/10.1175/JAS-D-13-0179.1.
- G. Feingold, and M. D. Shupe, 2015: The role of ice nuclei recycling in the maintenance of cloud ice in Arctic mixedphase stratocumulus. Atmos. Chem. Phys., 15, 10 631-10 643, https://doi.org/10.5194/acp-15-10631-2015.

—, M. D. Shupe, and N. B. Miller, 2017: Cloud-atmospheric boundary layer-surface interactions on the Greenland ice sheet during the July 2012 extreme melt event. J. Climate, 30, 3237-3252, https://doi.org/10.1175/JCLI-D-16-0071.1.

—, G. de Boer, J. M. Creamean, A. McComiskey, M. D. Shupe, M. Maahn, and C. Cox, 2018: The relative impact of cloud condensation nuclei and ice nucleating particle concentrations on phase-partitioning in Arctic mixed-phase stratocumulus clouds. Atmos. Chem. Phys., 18, 17 047-17 059, https://doi.org/ 10.5194/acp-18-17047-2018.

Stevens, R. G., and Coauthors, 2018: A model intercomparison of CCNlimited tenuous clouds in the high Arctic. Atmos. Chem. Phys., 18, 11 041-11 071, https://doi.org/10.5194/acp-18-11041-2018.

Stuecker, M. F., and Coauthors, 2018: Polar amplification dominated by local forcing and feedbacks. Nat. Climate Change, $\mathbf{8}$, 1076-1081, https://doi.org/10.1038/s41558-018-0339-y.

Tan, I., and T. Storelvmo, 2019: Evidence of strong contributions from mixed-phase clouds to Arctic climate change. Geophys. Res. Lett., 46, 2894-2902, https://doi.org/10.1029/2018GL081871. - — - and M. Zelinka, 2016: Observational constraints on mixed-phase clouds imply higher climate sensitivity. Science, 352, 224-227, https://doi.org/10.1126/science.aad5300.

Tjernström, M., and Coauthors, 2015: Warm-air advection, air mass transformation and fog causes rapid ice melt. Geophys. Res. Lett., 42, 5594-5602, https://doi.org/10.1002/2015GL064373.

- M. D. Shupe, I. M. Brooks, P. Achtert, J. Prytherch, and J. Sedlar, 2019: Arctic summer airmass transformation, surface inversions, and the surface energy budget. J. Climate, 32, 769789, https://doi.org/10.1175/JCLI-D-18-0216.1.

Tripoli, G. J., and W. R. Cotton, 1981: The use of ice-liquid water potential temperature as a thermodynamic variable in deep atmospheric models. Mon. Wea. Rev., 109, 1094-1102, https:// doi.org/10.1175/1520-0493(1981)109<1094:TUOLLW>2.0.CO;2.

Wegener, A., 1911: Thermodynamik der Atmosphaere. J. A. Barth, Leipzig, 331 pp.

Wieringa, J., 1980: Representativeness of wind observations at airports. Bull. Amer. Meteor. Soc., 61, 962-971, https://doi.org/ 10.1175/1520-0477(1980)061<0962:ROWOAA > 2.0.CO;2.

Wood, R., and D. L. Hartmann, 2005: Spatial variability of liquid water path in marine low cloud: Part II. Geographic distribution and dependence upon large-scale parameters. https:// atmos.washington.edu/ robwood/papers/my_papers/lwp_pdf_ paper_part2.pdf.

Woods, C., and R. Caballero, 2016: The role of moist intrusions in winter arctic warming and sea ice decline. J. Climate, 29, 44734485, https://doi.org/10.1175/JCLI-D-15-0773.1.

Yang, W., and G. Magnusdottir, 2017: Springtime extreme moisture transport into the Arctic and its impact on sea ice concentration. J. Geophys. Res. Atmos., 122, 5316-5329, https:// doi.org/10.1002/2016JD026324.

Young, G., and Coauthors, 2016: Observed microphysical changes in Arctic mixed-phase clouds when transitioning from sea ice to open ocean. Atmos. Chem. Phys., 16, 13 945-13 967, https:// doi.org/10.5194/acp-16-13945-2016.

, P. J. Connolly, C. Dearden, and T. W. Choularton, 2018: Relating large-scale subsidence to convection development in Arctic mixed-phase marine stratocumulus. Atmos. Chem. Phys., 18, 1475-1494, https://doi.org/10.5194/acp-18-1475-2018. 